\title{
Damping Properties of Ethylene-Vinyl Acetate Rubber/Polylactic Acid Blends
}

\author{
Xiaozhen He, Ming Qu, Xinyan Shi* \\ Key Laboratory of Rubber-Plastics, Ministry of Education/Shandong Provincial Key Laboratory of Rubber and \\ Plastics, Qingdao University of Science and Technology, Qingdao, China \\ Email: "lindashi88@hotmail.com
}

Received 22 January 2016; accepted 20 March 2016; published 23 March 2016

Copyright @ 2016 by authors and Scientific Research Publishing Inc.

This work is licensed under the Creative Commons Attribution International License (CC BY). http://creativecommons.org/licenses/by/4.0/

(c) (i) Open Access

\begin{abstract}
In this research, ethylene-vinyl acetate rubber (EVM)/polylactic acid (PLA) $=80 / 20$ by weight blend was compounded with silica in a Haake torque rheometer. The effects of hindered phenol (A0-60), super branched polyol, petroleum resin C9, polyvinyl chloride (PVC) and acrylic rubber (ACM) on the damping properties of blends were investigated by dynamic mechanic analyzer (DMA). The results showed that $20 \mathrm{phr}$ super branched polyol significantly increased the damping factor of PLA to widen the effective damping temperature range from $42.1^{\circ} \mathrm{C}$ to $102.5^{\circ} \mathrm{C} .15 \mathrm{phr} \mathrm{AO}$ 60 and $10 \mathrm{phr}$ petroleum resin $\mathrm{C} 9$ both dramatically raised the blend's damping factor to broaden the effective damping temperature range to $98.0^{\circ} \mathrm{C}$ and $102.6^{\circ} \mathrm{C}$, respectively. ACM and PVC are compatible with EVM, and both improved the damping properties of EVM/PLA blends.
\end{abstract}

\section{Keywords}

DMA, EVM/PLA, Damping, Organic Hybrid

\section{Introduction}

Polymeric damping materials are functional materials having polymer matrices and are widely used for vibration and noise reduction [1]-[3]. The height and width of the $\tan \delta$ peak at the glass transition zone are the two main factors for assessing the damping ability of a material. In general, homopolymers possess efficient damping ability in a temperature range of only $20^{\circ} \mathrm{C}-30^{\circ} \mathrm{C}$ around the glass-transition temperature Tg [4]. However, for outdoor or machinery applications, good damping materials should exhibit a high loss factor $(\tan \delta \geq 0.3)$ over a wide temperature range [5]-[7]. In order to meet this particular requirement, typically, a low $\mathrm{Tg}$ and a high $\mathrm{Tg}$ polymer are combined together by blending (including solution and mechanical blending) or as block or graft copolymers, as interpenetrating networks, etc. [8]. Organic hybrid polymers are also an effective way to improve

*Corresponding author.

How to cite this paper: He, X.Z., Qu, M. and Shi, X.Y. (2016) Damping Properties of Ethylene-Vinyl Acetate Rubber/Polylactic Acid Blends. Journal of Materials Science and Chemical Engineering, 4, 15-22.

http://dx.doi.org/10.4236/msce.2016.43003 
the damping properties of polymers [9]-[13].

Ethylene-vinyl acetate rubber (VA content of more than 40\%, EVM) [14] [15] is a polar saturated rubber with a large number of polar ester side groups, which impart a high loss factor (ca. 0.93). The glass transition zone of EVM is between $-5^{\circ} \mathrm{C}$ and $30^{\circ} \mathrm{C}$, which is a typical temperature range for damping applications. EVM is also inherent flame retardant making it an ideal material for damping elements. However, the effective damping temperature range (EDTR) is too narrow to make it suitable for many applications. As a result, it is not widely used. Polylactic acid (PLA) [16]-[18] is a biodegradable and environment-friendly polymer with abundant ester groups along the main chain. PLA has a high damping factor $(\tan \delta=2.2)$, and its glass transition lies between $55^{\circ} \mathrm{C}$ and $70^{\circ} \mathrm{C}$. Adding PLA can widen the damping temperature range of EVM, and it is an effective way to design a damping material with abroad temperature range [19]-[21].

In this work, EVM/PLA = 80/20 was chosen as blend matrix having abundant ester groups (hydrogen bond accepters). Hindered phenol AO-60, super branched polyol (made in our laboratories) and petroleum resin C9 with molecular weights of 1177, 1101 and 2000 were chosen as the organic hybrid agents for EVM/PLA blends due to their mode rate molecular weight as well as the abundant hydroxyl groups (in AO-60 and the polyol), which could act as hydrogen bond donors. PVC and ACM both with high damping factors were used as a third polymer component in the EVM/PLA blends to examine the effects on the damping properties. The aim was to prepare high performance damping materials with wider damping temperature ranges.

\section{Experimental}

\subsection{Materials}

Ethylene-vinyl acetate rubber (EVM): Levapren 700, vinyl acetate content of $70 \mathrm{wt} \%$, Lanxess Deutschland GmbH, Leverkusen, Germany; polylactic acid (PLA): 2003D, Nature Works, USA; dicumyl peroxide (DCP): Rhenocure VC-40CC, 40\% wt on an inert carrier; triallylisocyanurate (TAIC): Rhenofit TAIC/s; polycarbodimide (PCD): Stabaxol P; DCP, TAIC and PCD were all provided by Rhein Chemie Qingdao, China; silica 1165 MP: specific surface area $165 \mathrm{~m}^{2} / \mathrm{g}$, Rhodia, Qingdao, China; AO-60 (antioxidant 1010, Hindered phenol): Haihua Qingdao, China; super branched polyol was made in our laboratory (as shown in Figure 1); petroleum resin C9: Puyang Chemical Co. Ltd., Henan, China; ACM: East Asia, Japan; PVC: Zhongtai, Xinjiang, China.

\subsection{Blend Recipe}

The variable elements of the blend recipe include: EVM 80 phr, PLA 20 phr, PCD 2 phr, $\mathrm{SiO}_{2} 30$ phr, DCP 1.5 phr, TAIC 0.5 phr; AO-60, polyol, C9, ACM and PVC.

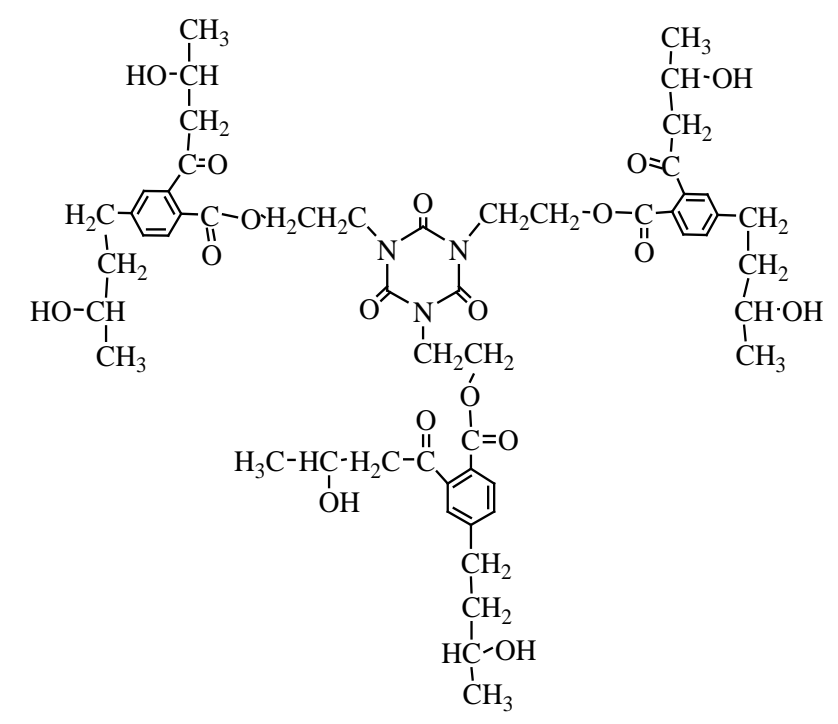

Figure 1. Structure of the super branched polyol. 


\subsection{Sample Preparation}

EVM and PLA were first mixed in a Haake Rheomix 30,000 s mixer at a rotor speed of $50 \mathrm{rpm}$ for $5 \mathrm{~min}$ at $160^{\circ} \mathrm{C}$. Then, premixed filler and additive were added and mixed for 7 more minutes. The blends were taken out of the mixer and processed at room temperature with DCP and TAIC on an SK-160B two-roll mill manufactured by Shanghai Plastics and Rubber Machinery Factory, China, before finally being molded into sheets in a VC-150T-FTMO-3RTvacuum press manufactured by Jiaxin Electric Company, China, at $170^{\circ} \mathrm{C}$ for $10 \mathrm{~min}$.

\subsection{Measurements}

The dynamic mechanical analysis was carried out using a Netzsch DMA 242 Dynamic Mechanical Analyzer, manufactured by Netzsch Company, Germany, from $-60^{\circ} \mathrm{C}$ to $180^{\circ} \mathrm{C}$ at a rate of $3 \mathrm{~K} / \mathrm{min}$ and a fixed frequency of $1 \mathrm{~Hz}$ in a double cantilever deformation mode.

\section{Result and Discussion}

\subsection{The Effects of A0-60 on the Damping Properties of EVM/PLA Blends}

Figure 2 shows the Tan $\delta$-T curve of blends with $15 \mathrm{phr}$ of AO-60. Some key data from Figure 1 are summarized in Table 1. It can be seen that AO-60 significantly increased the blend's $\tan \delta$ and the effective damping temperature range (EDTR) of EVM/PLA was broadened from $42.1^{\circ} \mathrm{C}$ to $98.0^{\circ} \mathrm{C}$. The two glass transition temperatures (peak1 and peak2) were shifted closer together. It was concluded that AO-60 has strong hydrogen bond interaction with both polymers in the EVM/PLA blend [9] [10]. During the dynamic mechanical testing, hydrogen bonds dissociate and reform, consuming a lot of energy. Thus, the loss factor increases and the damping properties improve. In addition, during heating, AO-60 molecules move at lower temperature and more easily due to their lower molecular weight (1177) compared with the polymer molecules. This leads to an increase intermolecular friction and more effective damping [10].

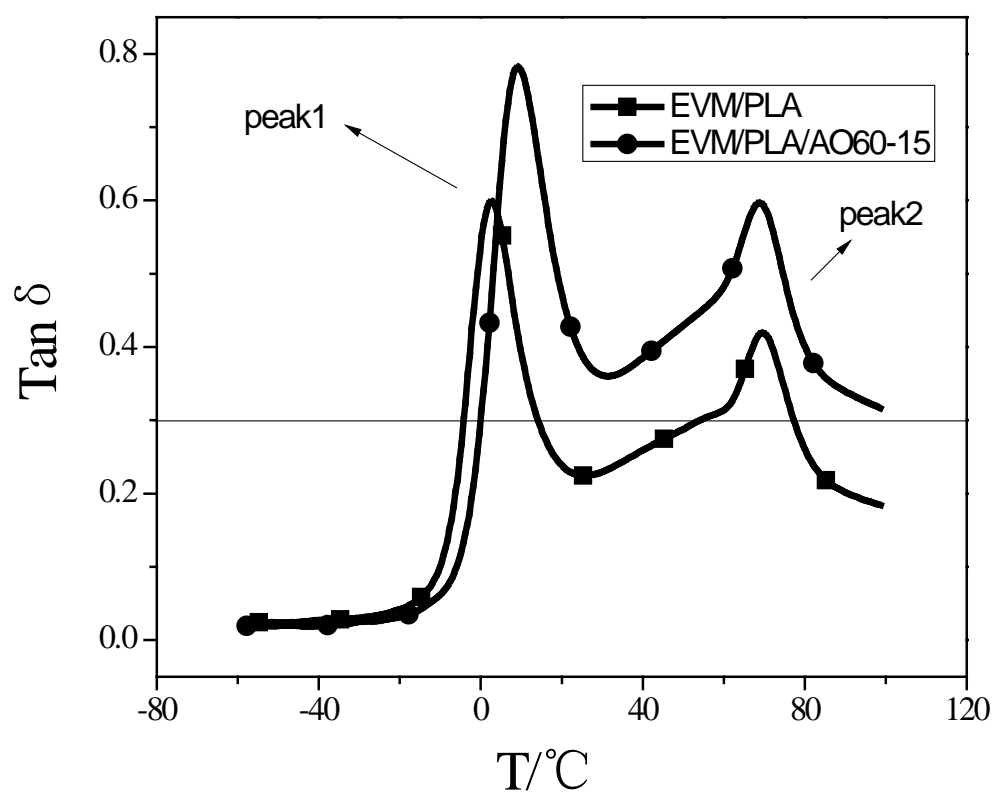

Figure 2. Effects of AO-60 on the damping factor of EVM/PLA blends.

Table 1. Effects of AO-60 on the damping factor of blends.

\begin{tabular}{cccccc} 
Composites & Peak1 $/{ }^{\circ} \mathbf{C}$ & Tan $\boldsymbol{~}_{\max }$ value 1 & Peak2 ${ }^{\circ} \mathbf{C}$ & Tan $\boldsymbol{\delta}_{\max }$ value $\mathbf{2}$ & $\mathbf{E D T R} /{ }^{\circ} \mathbf{C}(\mathbf{T a n} \boldsymbol{\delta} \geq \mathbf{0 . 3})$ \\
\hline EVM/PLA & 2.5 & 0.594 & 69.7 & 0.418 \\
EVM/PLA/AO60-15 & 9.7 & 0.779 & 69.2 & 0.596 \\
\hline
\end{tabular}


It also can be seen that the difference between Tg of EVM and Tg of PLA (peak1-peak2) became smaller indicating that AO-60 acts as a compatibilizer for EVM and PLA.

\subsection{The Effects of Polyol on the Damping Properties of EVM/PLA Blends}

Figure 3 shows the Tan $\delta$-T curve of blends with 20 phr of polyol. Some key data from Figure 3 are summarized in Table 2. It can be seen that the polyol dramatically increased the damping factor of PLA and broadened the effective damping temperature range of EVM/PLA blends from $42.1^{\circ} \mathrm{C}$ to $102.5^{\circ} \mathrm{C}$. The Tg of PLA shifted a little to lower temperature but that of EVM remained unchanged. We infer that the polyol has stronger hydrogen bond interaction with PLA than with EVM [22] and the improvement of the damping properties of the blend can be essentially attributed to the intermolecular friction between the polyol and the polymer matrix due to the polyol's inherent dynamic mechanic behavior [23].

\subsection{The Effects of Petroleum Resin C9 on the Damping Properties of EVM/PLA Blends}

Figure 4 shows the Tan $\delta$-T curve of blends with $10 \mathrm{phr}$ amounts of C9. Some key data from Figure 5 are summarized in Table 3. It can be seen that 10 phr C9 significantly increased the blend's damping factor and widened the effective damping temperature range from $42.1^{\circ} \mathrm{C}$ to $102.6^{\circ} \mathrm{C}$. Both $\mathrm{Tg}$ shifted to higher temperature. It is known that there are no hydrogen bond donors in C9. Thus, the improvement to the damping properties of the blend with C9 must derive from its own dynamic mechanic behavior due to its moderate molecular weight, which is comparable with that of AO-60 [24].

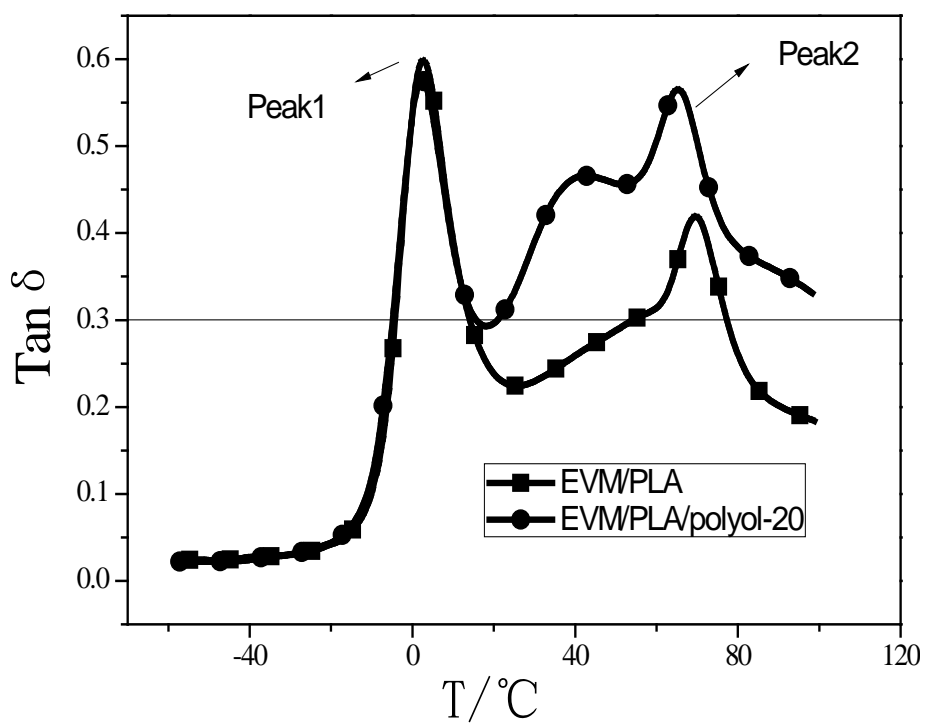

Figure 3. Effects of polyol on the damping factor of EVM/PLA blends.

Table 2. Effects of polyol on the damping factor of blends.

\begin{tabular}{cccccc}
\hline Composites & Peak1 $/{ }^{\circ} \mathbf{C}$ & Tan $\boldsymbol{\delta}_{\text {max }}$ value $\mathbf{1}$ & Peak2 $/{ }^{\circ} \mathbf{C}$ & $\operatorname{Tan} \boldsymbol{\delta}_{\text {max }}$ value 2 & $\mathbf{E D T R} /{ }^{\circ} \mathbf{C}(\operatorname{Tan} \boldsymbol{\delta} \geq \mathbf{0 . 3})$ \\
\hline EVM/PLA & 2.5 & 0.594 & 69.7 & 0.418 & 42.1 \\
EVM/PLA/polyol-20 & 2.8 & 0.575 & 64.8 & 0.564 & 102.5 \\
\hline
\end{tabular}

Table 3. Effects of C9 on the damping factor of blends.

\begin{tabular}{cccccc}
\hline Composites & Peak1 $/{ }^{\circ} \mathbf{C}$ & Tan $\boldsymbol{\delta}_{\max }$ value 1 & Peak2 $/{ }^{\circ} \mathbf{C}$ & Tan $\boldsymbol{\delta}_{\max }$ value 2 & EDTR $/{ }^{\circ} \mathbf{C}(\mathbf{T a n} \boldsymbol{\delta} \geq \mathbf{0 . 3})$ \\
\hline EVM/PLA & 2.5 & 0.594 & 69.7 & 0.418 \\
EVM/PLA/C9-10 & 6.9 & 0.699 & 72.4 & 0.533 \\
\hline
\end{tabular}




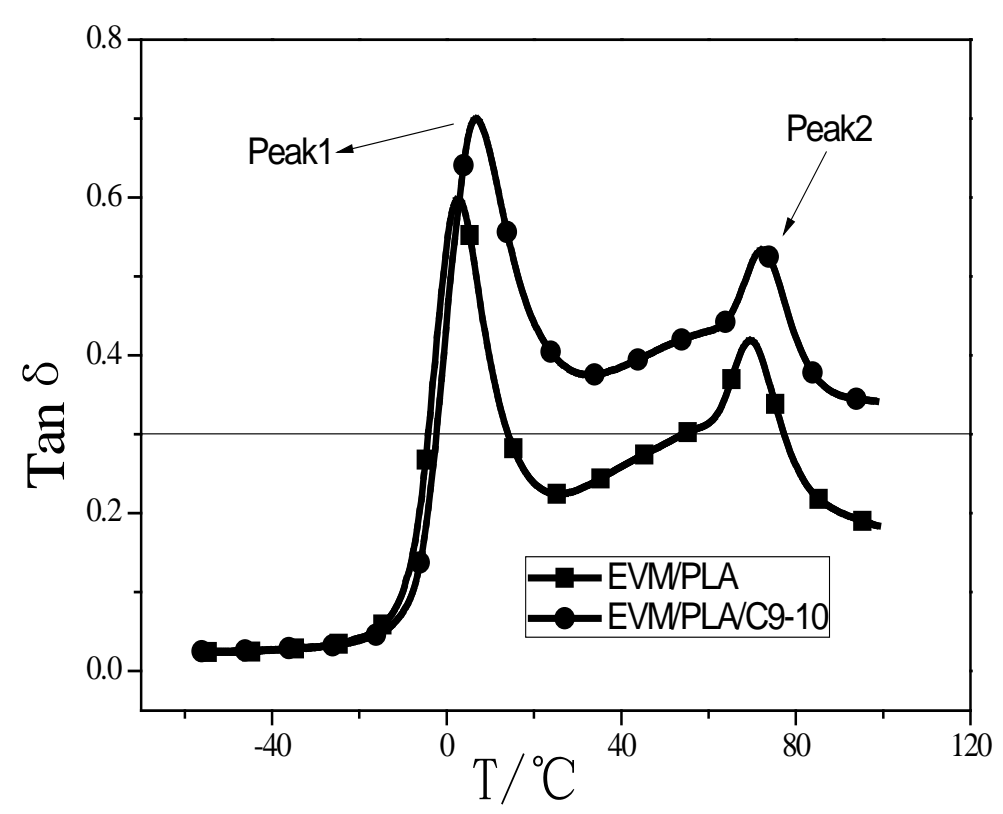

Figure 4. Effects of C9 on the damping factor of EVM/PLA blends.

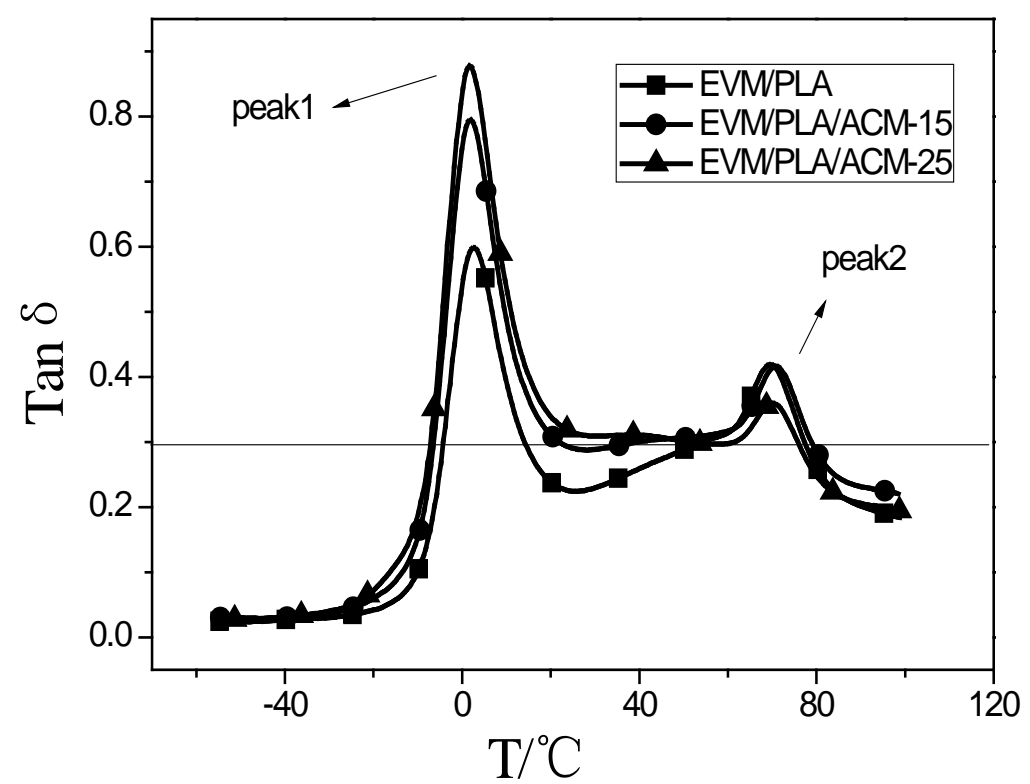

Figure 5. Effects of ACM on the damping factor of EVM/PLA blends.

\subsection{The Effects of ACM on the Damping Properties of EVM/PLA Blends}

The Tan $\delta$-T curves of blends with different amounts of ACM are shown in Figure 5. Some key data from Figure 5 are summarized in Table 4. It can be seen that 15 phr ACM broadened the effective damping temperature range from $42.1^{\circ} \mathrm{C}$ to $57.7^{\circ} \mathrm{C}$ due to increasing the breadth of EVM's damping peak. 25 phr ACM further widened the effective damping temperature range of blend to $81.7^{\circ} \mathrm{C}$ due to further increasing the breadth EVM's damping peak. Moreover, the Tg of EVM shifted to slightly lower temperature with the addition of ACM.

The glass transition temperature of ACM is about $-15^{\circ} \mathrm{C}$ and ACM has similar molecular structure to EVM, they are both polar. Only a single glass transition temperature could be observed around Peak1. Furthermore, peak 1 was increased dramatically in area with increasing ACM content. All this suggests that ACM and EVM are compatible. 


\subsection{The Effects of PVC on the Damping Properties of EVM/PLA Blends}

The Tan $\delta$-T curves of blends with different amounts of PVC are shown in Figure 6. Some key data from Figure 6 are summarized in Table 5. It can be seen that 15 phr PVC increased the blend's damping factor and broadened the effective damping temperature range from $42.1^{\circ} \mathrm{C}$ to $76.9^{\circ} \mathrm{C}$.The $\mathrm{Tg}$ of $\mathrm{EVM}$ was shifted to higher temperature. 25 phr PVC shifted the Tg of EVM to even higher temperature but did not further increase the damping value.

The glass transition temperature of PVC is at ca. $78^{\circ} \mathrm{C}$, from previous studies [10] it is known that PVC exhibits good compatibility with EVM700. Thus, no new relaxation peak between peak1 and peak2 is observed in Figure 6 and the EVM Tg peak simply shifts to higher temperature. The Tg peak of PLA didn't move, which can be taken as evidence that PVC and PLA are not compatible.

\section{Conclusion}

15 phr AO-60 significantly increased the damping factor of an EVM/PLA blend to broaden the effective damping temperature range from $42.1^{\circ} \mathrm{C}-98^{\circ} \mathrm{C}$. The $20 \mathrm{phr}$ super branched polyol was able to significantly raise PLA's damping factor without shifting the Tg of the polymers but nevertheless broadening the effective damp-

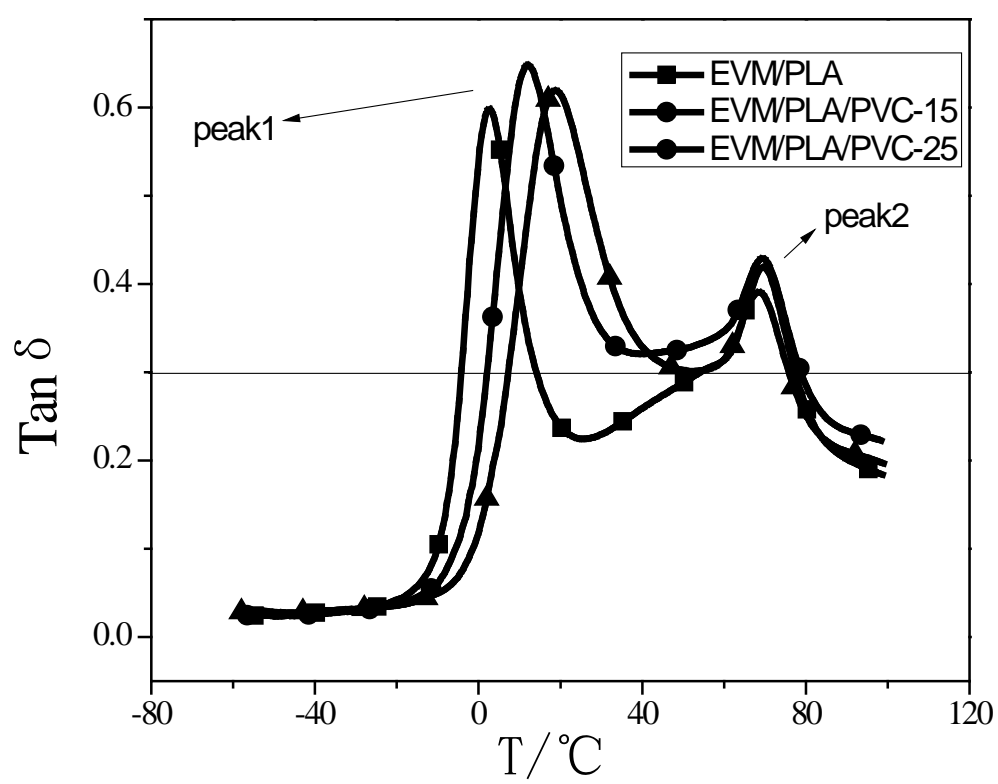

Figure 6. Effects of PVC on the damping factor of EVM/PLA blends.

Table 4. Effects of ACM on the damping factor of blends.

\begin{tabular}{cccccc}
\hline Composites & Peak1 $/{ }^{\circ} \mathbf{C}$ & Tan $\boldsymbol{~}_{\max }$ value 1 & Peak2/ ${ }^{\circ} \mathbf{C}$ & Tan $\boldsymbol{\delta}_{\max }$ value 2 & EDTR/ $/{ }^{\circ}(\operatorname{Tan} \boldsymbol{\delta} \geq \mathbf{0 . 3})$ \\
\hline EVM/PLA & 2.5 & 0.594 & 69.7 & 0.418 & 42.1 \\
EVM/PLA/ACM-15 & 1.5 & 0.792 & 69.7 & 0.419 & 57.7 \\
EVM/PLA/ACM-25 & 1.7 & 0.878 & 70.2 & 0.359 & 81.7 \\
\hline
\end{tabular}

Table 5. Effects of PVC on damping factor of blends.

\begin{tabular}{cccccc}
\hline Composites & Peak1 $/{ }^{\circ} \mathbf{C}$ & Tan $\boldsymbol{\delta}_{\max }$ value 1 & Peak2 $/{ }^{\circ} \mathbf{C}$ & Tan $\boldsymbol{\delta}_{\max }$ value 2 & EDTR/ $\mathbf{C}(\mathbf{T a n} \boldsymbol{\delta} \geq \mathbf{0 . 3})$ \\
\hline EVM/PLA & 2.5 & 0.594 & 69.7 & 0.418 \\
EVM/PLA/PVC-15 & 11.6 & 0.651 & 69.7 & 0.433 \\
EVM/PLA/PVC-25 & 19.0 & 0.616 & 68.6 & 0.391 \\
\hline
\end{tabular}


ing temperature range to $102.5^{\circ} \mathrm{C} .10 \mathrm{phr}$ petroleum resin C9 significantly increased the damping factor of EVM/PLA blends to broaden the effective damping temperature range from $42.1^{\circ} \mathrm{C}$ to $102.6^{\circ} \mathrm{C} .25 \mathrm{phr} \mathrm{ACM}$ increased the damping factor of EVM to broaden the effective damping temperature range to $81.7^{\circ} \mathrm{C}$; $15 \mathrm{phr}$ PVC increased the damping factors of EVM and PLA to widen the effective damping temperature range to $76.9^{\circ} \mathrm{C}$ and shifted the Tg of EVM to higher temperature. ACM and PVC are both compatible with EVM700.

\section{Acknowledgements}

The authors would like to acknowledge the support of National Natural Science Foundation of China (51273101) and Shandong Science and Technology Program for Universities (J12LA14) without which the work presented in this article would not have been possible.

\section{References}

[1] Wang, H.Q., Jiang, Z.G., Huang, L., et al. (2006) Development of Damping Materials. Chinese Polymer Bulletin, 3, 24-30.

[2] Jones, D.I.G. (1974) Temperature-Frequency Dependence of Dynamic Properties of Damping Materials. Journal of Sound and Vibration, 33, 451-470. http://dx.doi.org/10.1016/S0022-460X(74)80228-2

[3] Corsaro, R.D. and Sperling, L.H. (1990) Sound and Vibration Damping with Polymers. American Chemical Society, Washington DC. http://dx.doi.org/10.1021/bk-1990-0424

[4] Wu, C., Wei, C., Guo, W. and Wu, C. (2008) Dynamic Mechanical Properties of Acrylic Rubber Blended with Phenolic Resin. Journal of Applied Polymer Science, 109, 2065-2070. http://dx.doi.org/10.1002/app.24371

[5] Mok, M., Kim, J. and Torkelson, J.M. (2008) Gradient Copolymers with Broad Glass Transition Temperature Regions: Design of Purely Interphase Compositions for Damping Applications. Journal of Polymer Science, Part B: Polymer Physics, 46, 48-58. http://dx.doi.org/10.1002/polb.21341

[6] Wu, J.H., Li, C.H., Chiu, H.T., Shong, Z.J. and Tsai, P.A. (2009) Reinforcement of Dynamically Vulcanized EPDM/PP Elastomers Using Organoclay Fillers: Dynamic Properties of Rubber Vibration Isolators and Anti-Vibration Performance. Journal of Thermoplastic Composite Materials, 22, 503-509.

http://dx.doi.org/10.1177/0892705709105966

[7] Kaneko, H., Inoue, K., Inoue, Y., Asai, S. and Sumita, M. (2002) Damping Performance of Polymer Blend/Organic Filler Hybrid Materials with Selective Compatibility. Material Letter, 52, 96-99. http://dx.doi.org/10.1016/S0167-577X(01)00373-1

[8] Li, S. and Zeng, W. (2002) Effect of Crosslinker, Buffer, and Blending on Damping Properties of Poly(styrene-acrylonitrile)/Poly(ethyl acrylate-n-butyl acrylate) Latex Interpenetrating Polymer Network. Journal of Applied Polymer Science, 84, 2347-2351. http://dx.doi.org/10.1002/app.10388

[9] Wu, C., Yamagishi, T.A. and Nakamoto, Y. (2000) Organic Hybrid of Chlorinated Polyethylene and Hindered Phenol. I. Dynamic Mechanical Properties. Journal of Polymer Science Part B: Polymer Physics, 38, 2285-2295. http://dx.doi.org/10.1002/1099-0488(20000901)38:17<2285::AID-POLB90>3.0.CO;2-X

[10] Wu, C., Yamagishi, T.A. and Nakamoto, Y. (2000) Organic Hybrid of Chlorinated Polyethylene and Hindered Phenol. II. Influence of the Chemical Structure of Small Molecules on Viscoelastic Properties. Journal of Polymer Science Part B: Polymer Physics, 38, 1496-1503. http://dx.doi.org/10.1002/(SICI)1099-0488(20000601)38:11<1496::AID-POLB90>3.0.CO;2-X

[11] Wu, C. and Akiyama, S. (2002) Enhancement of Damping Performance of Polymers by Functional Small Molecules. Chinese Journal of Polymer Science, 20, 119-128.

[12] Wu, C.F. (2001) Discovery of Multi-Function in Organic Hybrid of Polarized Polymers and Hindered Phenol. Journal of Materials Science Letters, 20, 1389-1391. http://dx.doi.org/10.1023/A:1011683225127

[13] Wu, C.F. (2003) Interphase Migration of a Hindered Phenol Compound in Acrylate Rubber/Chlorinated Polypropylene Blend on Dynamic Mechanical Properties. Polymer Journal, 35, 286-289. http://dx.doi.org/10.1295/polymj.35.286

[14] Shi, X., Bi, W. and Zhao, S. (2011) Study on the Damping of EVM Based Blends. Journal of Applied Polymer Science, 120, 1121-1125. http://dx.doi.org/10.1002/app.33260

[15] Shi, X., Bi, W. and Zhao, S. (2011) Damping Properties of Blends Based on EVM. Journal of Macromolecular Science, Part B, 50, 1928-1938. http://dx.doi.org/10.1080/00222348.2011.575029

[16] Lee, S.T., Kareko, L. and Jun, J. (2008) Study of Thermoplastic PLA Foam Extrusion. Journal of Cellular Plastics, 44, 293-305. http://dx.doi.org/10.1177/0021955X08088859

[17] Rizvi, R., Cochrane, B. and Naguib, H. (2011) Fabrication and Characterization of Melt-Blended Polylactide-Chitin 
Composites and Their Foams. Journal of Cellular Plastics, 47, 283-300.

[18] Zhang, J. (2010) Polylactic Acid (PLA) Thickening Modified Its Preparation and Properties of Foamed Materials Research. Shanghai Jiaotong University, Shanghai.

[19] Shi, X. and Bi, W. (2011) Damping Properties of Ethylene-Vinyl Acetate Rubber/Nitrile Butadiene Rubber Blends. Journal of Macromolecular Science, Part B: Physics, 50, 417-426. http://dx.doi.org/10.1080/00222341003772266

[20] Shi, X., Liang, Y., Zhang, P. and Zhao, S. (2006) Properties of Thermoplastic Polyurethane and Ethylene-Vinyl Acetate Copolymer Blends. Synthetic Rubber Industry, 29, 458-461.

[21] Shi, X., Bi, W. and Zhao, S. (2011) DMA Analysis of the Damping of Ethylene-Vinyl Acetate/Acrylonitrile Butadiene Rubber Blends. Journal of Applied Polymer Science, 124, 2234-2239. http://dx.doi.org/10.1002/app.35301

[22] Shi, X., Li, Q., Fu, G. and Jia, L. (2014) The Effects of a Polyol on the damping Properties of EVM/PLA Blends. Polymer Testing, 33, 1-6. http://dx.doi.org/10.1016/j.polymertesting.2013.10.007

[23] Wu, C. (2001) Functional Design of Organic Hybrids Consisting of Polarized Polymers and Hindered Phenol. Journal of Materials Science Letters, 20, 1389-1391. http://dx.doi.org/10.1023/A:1011683225127

[24] Ding, X., Zhang, H. and Yan, X. (2008) Effect of the State of Organic Small Molecule in Hybrid Materials on Damping Properties. Journal of Materials Engineering, 4, 8-10. 